Received August 11, 2021

Revised December 10, 2021

Accepted December 16, 2021

\author{
Corresponding author \\ Gunn Hee Kim, M.D., Ph.D. \\ Department of Anesthesia and Pain \\ Medicine, National Medical Center, 245 \\ Eulji-ro, Jung-gu, Seoul 04564, Korea \\ Tel: 82-2-2260-7368 \\ Fax: 82-2-2260-7374 \\ E-mail: gunnhee.kim@nmc.or.kr \\ This study was presented at the \\ KoreAnesthesia 2020 (The 97th Annual \\ Scientific Meeting of the Korean Society of \\ Anesthesiologists), Nov 5 (Thu)-7 (Sat), \\ 2020, Grand Hyatt Incheon, Korea.
}

\section{Comparison of two-lung and one-lung ventilation in bilateral video-assisted thoracoscopic extended thymectomy in myasthenia gravis: a retrospective study}

\author{
Mijung Yun', Gunn Hee Kim¹, Sung-chul Ko', Yun Jae Han', and \\ Wooshik Kim²
}

Departments of ${ }^{1}$ Anesthesia and Pain Medicine, ${ }^{2}$ Cardiothoracic Surgery, National Medical Center, Seoul, Korea

\begin{abstract}
Background: Myasthenia gravis (MG) is an autoimmune disease, and early thymectomy is recommended. Since the introduction of video-assisted thoracoscopic surgery, the safety and effectiveness of carbon dioxide insufflation in the thoracic cavity (capnothorax) has been controversial. This study aimed to compare the safety and effectiveness of ventilation methods in bilateral video-assisted thoracoscopic extended thymectomy (BVET) with capnothorax.
\end{abstract}

Methods: We retrospectively investigated the medical records of patients with MG who underwent BVET between August 2016 and January 2018. Patients were divided into two groups: group $D(n=26)$ for one-lung ventilation and group $S(n=28)$ for two-lung ventilation. We set nine anesthesia time points (TO-T8) and collected respiratory and hemodynamic variables, including arterial $\mathrm{O}_{2}$ index $\left(\mathrm{PaO}_{2} / \mathrm{FiO}_{2}\right)$.

Results: $\mathrm{SpO}_{2}$ at $\mathrm{T} 1-\mathrm{T} 3$ and $\mathrm{T} 8$ was significantly lower in group $\mathrm{D}$ than in group $\mathrm{S}$. The $\mathrm{FiO}_{2}$ in group $\mathrm{S}$ was lower than that in group $\mathrm{D}$ at all time points. The number of $\mathrm{PaO}_{2} / \mathrm{FiO}_{2} \leq 300$ and $\mathrm{PaO}_{2} / \mathrm{FiO}_{2} \leq 200$ events was significantly higher in group $\mathrm{D}$ than in group S. Hemodynamic variables were not significantly different between the two groups at any time point. The duration of surgery and anesthesia was shorter in group $S$ than in group D.

Conclusions: This retrospective study suggests that anesthesia using two-lung ventilation during BVET with capnothorax is a safe and effective method to improve lung oxygenation and reduce anesthesia time.

Keywords: Myasthenia gravis; One-lung ventilation; Thymectomy; VATS.

\section{INTRODUCTION}

Myasthenia gravis (MG) is an autoimmune disease that affects nicotinic acetylcholine receptors in neuromuscular junctions. It mainly affects women in their 20 s and 30 s and can be treated with medical or surgical treatment. Generally, early thymectomy is recommended for early onset MG [1,2].

After Dr. Alfred Blalock succeeded in performing thymectomy in thymomatous MG patients using upper partial midline sternotomy in 1936, thymectomy in MG patients began to be widely performed [3]. However, sternotomy was accompanied by several side effects, such as bleeding, longer

This is an Open Access article distributed under the terms of the Creative Commons Attribution Non-Commercial License (http://creativecommons.org/licenses/by-nc/4.0) which permits unrestricted non-commercial use, distribution, and reproduction in any medium, provided the original work is properly cited.

Copyright (C) the Korean Society of Anesthesiologists, 2022 
duration of hospitalization, and cosmetic problems. In the 1990s, video-assisted thoracic surgery (VATS) became popular and was introduced in various thoracic and mediastinal surgeries, such as sympathectomy, esophageal resection, and thymectomy. VATS has been reported to reduce postsurgical pain, hospitalization, and treatment costs, while showing similar therapeutic effects to open thymectomy [4]. Therefore, VATS and robotic-assisted thymectomy are used by an increasing number of centers and are usually preferred by patients [5].

After the introduction of VATS, the safety and effectiveness of carbon dioxide $\left(\mathrm{CO}_{2}\right)$ insufflation in the thoracic cavity (capnothorax) remains controversial. Although studies have shown that capnothorax helps to secure the vision of the surgeon and does not significantly affect the patient's hemodynamic stability during anesthesia [6-8], other studies have also reported that capnothorax should be used only at low pressure, as it significantly affects the patient's hemodynamic and pulmonary stability $[9,10]$.

In our hospital, we have been performing capnothorax and one-lung ventilation (OLV) at the request of a thoracic surgeon since 2016, when bilateral VATS extended thymectomy (BVET) was introduced. However, we found that one-lung ventilation renders the maintenance of anesthesia very difficult; therefore, we decided to switch to two-lung ventilation using a single lumen tube after discussion with the surgeon.

We observed that there were differences in pulmonary function between the two anesthetic methods. Thus, this study aimed to compare the differences between the two anesthetic methods and to determine the appropriate anesthetic method.

The primary endpoint of our study was the arterial oxygen $\left(\mathrm{O}_{2}\right)$ index (partial pressure of arterial oxygen $\left[\mathrm{PaO}_{2}\right] /$ fraction of inspired oxygen $\left[\mathrm{FiO}_{2}\right]$ ) during anesthesia time for the evaluation of pulmonary oxygen exchange deficit. The secondary endpoints were operation and anesthesia time for effectiveness of the surgery.

\section{MATERIALS AND METHODS}

This retrospective study was approved by the research board (Institutional Review Board) of our center (no. H-1806091-003). We retrospectively investigated the medical records of patients with MG who underwent BVET between August 2016 and January 2018.

The inclusion criteria were as follows: age 18-65 years, American Society of Anesthesiologists physical status I-III, preoperative vital capacity (VC) > 2 L, no history of sternotomy, and no cardiovascular or pulmonary disease. Patients who underwent conversion from one-lung ventilation to two-lung ventilation or switched from VATS to sternotomy were excluded. We divided the patients into two groups: group D (the double-lumen tube group), with patients who underwent ventilation for one lung, and group $S$ (the single-lumen tube group), with those who underwent ventilation for two lungs during surgery. Ultimately, 83 patients were enrolled in the present study.

We set nine anesthesia time points (T0-T8) and collected the data. The time points were set as follows: T0 was immediately after tracheal intubation, T1 was the time of incision on the right side, $\mathrm{T} 2$ was set as 10 min after the $\mathrm{CO}_{2}$ insufflation of the right lung, T3 was set as $30 \mathrm{~min}$ from the right lung $\mathrm{CO}_{2}$ insufflation, T4 refers to the transition period from the right to the left side (in group D, two-lung ventilation), T5 the time of incision on the left side, $\mathrm{T} 6$ was set as $10 \mathrm{~min}$ after the $\mathrm{CO}_{2}$ insufflation of the left lung, T7 was set as 30 min after the left lung $\mathrm{CO}_{2}$ insufflation, and T8 referred to the end of the left side operation (in group D, two-lung ventilation). Two-lung ventilation was used at all time points in group $S$, and onelung ventilation was used at T1-T3/T5-T7 in group D.

The basic characteristics of the patients, such as age, sex, body mass index (BMI), American Society of Anesthesiologists physical status, Myasthenia Gravis Foundation of America (MGFA) class, operation, and anesthesia time were recorded. The end-tidal $\mathrm{CO}_{2}\left(\mathrm{EtCO}_{2}\right)$, peak inspiratory pressure (PIP), respiratory rate (RR), peripheral capillary oxygen saturation $\left(\mathrm{SpO}_{2}\right), \mathrm{FiO}_{2}$, mean blood pressure (MBP), heart rate (HR), and cardiac index (CI) were recorded at T0-T8, and all variables were compared at each time point. Because arterial blood gas analysis was mainly measured after onelung ventilation, $\mathrm{PaO}_{2}$ and arterial oxygen index $\left(\mathrm{PaO}_{2} / \mathrm{FiO}_{2}\right)$ were recorded at $\mathrm{T} 1$ and $\mathrm{T} 5$. Postoperative complications, intensive care unit (ICU) stay time, and hospitalization days (HD) were also recorded.

None of the patients received premedication. Intraoperative monitoring included noninvasive blood pressure measurement, invasive arterial blood pressure monitoring, electrocardiography, pulse oximetry, capnography, bispectral index (BIS) monitoring, and neuromuscular function assessment (TOF Watch SX monitor ${ }^{\circledR}$, Organon Ltd., Ireland). General anesthesia was induced using total intravenous anesthesia. Propofol and remifentanil were administered to end organ concentrations of 4-5 and 3-4 ng/ml, respectively, using a target-controlled infusion pump (Orchestra ${ }^{\circledR}$, Fresenius 
Vial, France). Rocuronium (0.6 mg/kg) was administered to facilitate intubation. In group D, a 35-F or 37-F left-sided double-lumen tube was inserted using videolaryngoscopy, and its correct position was confirmed by auscultation and eventually by bronchoscopy. In group S, a 7.0-mm or $8.0-\mathrm{mm}$ internal diameter single-lumen tube was inserted using videolaryngoscopy. Mechanical ventilation with $\mathrm{O}_{2}$ and $\operatorname{air}\left(\mathrm{FiO}_{2}\right.$, 0.5) was started with tidal volumes (TVs) of 8-10 ml/ $\mathrm{kg}$ and an initial RR of 9-10 breaths/ min. In group D, passive lung collapse and contralateral OLV were started immediately before the first trocar insertion. During OLV, the $\mathrm{FiO}_{2}$ was adjusted to $0.5-1.0$, the TV was reduced to $6-8 \mathrm{ml} / \mathrm{kg}$ to maintain a PIP of $<35 \mathrm{~cm} \mathrm{H}_{2} \mathrm{O}$, and the $\mathrm{RR}$ was increased to avoid respiratory acidosis. In group $\mathrm{S}$, the TV was reduced to 6-8 $\mathrm{ml} / \mathrm{kg}$. Propofol and remifentanil infusions were titrated to maintain an $\mathrm{MBP}$ within $20 \%$ of the baseline during anesthesia and to maintain a BIS $<50$. Rocuronium was continuously injected to maintain a train of four (TOF) count of 1 or 2 . A radial arterial pressure line was placed, and a central venous catheter was inserted via the right internal jugular vein. CI was monitored using a minimally invasive hemodynamic monitor (FloTrac System ${ }^{\circledR}$, Edwards Lifesciences, USA).

BVET was performed with patients in the supine position with a $15^{\circ}$ reverse Trendelenburg position. Both arms were placed at $90^{\circ}$ forearm abduction external rotation position without any pressure on the brachial plexus nerve. The rightside approach was performed first. First, a 5-mm trocar was placed along the upper edge of the fifth intercostal space in the midaxillary line. After inspection of the right thoracic cavity to evaluate the adhesions and pathology, $\mathrm{CO}_{2}$ insufflation was performed using a pressure limit of 8-14 $\mathrm{mmHg}$ and a flow rate of $4 \mathrm{~L} / \mathrm{min}$. Under thoracoscopic guidance, a second 5-mm trocar was inserted near the anterior axillary line of the sixth intercostal space, and a third 5-mm trocar was placed in the sixth or seventh intercostal space near the sternum without injury to the internal mammary vessel. The procedure on the left side was performed in the same manner.

At the end of the surgery, fentanyl ( $25 \mu \mathrm{g})$ was injected intravenously, and intravascular patient-controlled analgesia was used for postoperative pain control. Additionally, neuromuscular relaxation was reversed with sugammadex (2 $\mathrm{mg} / \mathrm{kg}$ ). After a TOF ratio $>0.9$, the tracheal tube was removed, and all patients were transferred to the ICU.

\section{Statistical analyses}

The Statistical Package for the Social Sciences program version 26.0 (IBM, USA) was used for statistical analysis. Variables with a normal distribution are indicated by the mean value (standard deviation), and variables with a non-normal distribution are indicated by the median (1Q, 3Q). Normality was tested using the Shapiro-Wilk test. The Student's unpaired $t$-test and Mann-Whitney $U$ test were used for continuous variables (operation time and anesthesia time), and the chi-squared test was used for categorical variables (arterial oxygen index). Statistical significance was set at $\mathrm{P}<0.05$.

\section{RESULTS}

A total of 29 of the 83 patients were excluded from the analysis due to incomplete data. Therefore, the data of 54 patients were analyzed with 26 and 28 patients in groups D and S, respectively.

Age, sex, weight, height, BMI, MGFA class, and American Society of Anesthesiologists physical status were not significantly different between the two groups (Table 1). However, the duration of surgery and anesthesia was longer in group $\mathrm{D}$ than in group S. The durations of ICU and HD were not significantly different between the two groups.

The respiratory variables are presented in Table 2 . The $\mathrm{EtCO}_{2}$ values at T0 were not significantly different between the two groups but were maintained at a higher level during surgery in group D, although statistical significance was only observed in T1-T3 and T7. The $\mathrm{SpO}_{2}$ at T1-T3 and T8 was significantly lower in group $\mathrm{D}$ than in group $\mathrm{S}$. The $\mathrm{FiO}_{2}$ was lower in group $\mathrm{S}$ than in group $\mathrm{D}$ at all time points. PIP and RR were not significantly different between the two groups at any time point. The number of $\mathrm{PaO}_{2} / \mathrm{FiO}_{2} \leq 300$ and $\mathrm{PaO}_{2} / \mathrm{FiO}_{2} \leq 200$ was significantly higher in group $\mathrm{D}$ than in group S (Table 3).

The hemodynamic variables are shown in Table 4. MBP, $\mathrm{HR}$, and CI were not significantly different between the two groups at any time point.

No complications were presumed to be related to myasthenic crisis in either group.

\section{DISCUSSION}

As a result of the study, the duration of the operation and anesthesia in group $\mathrm{S}$ was short, and $\mathrm{SpO}_{2}>90 \%$ was maintained even when the $\mathrm{FiO}_{2}$ level was lower in group $\mathrm{S}$ than that in group $\mathrm{D}$. The number of $\mathrm{PaO}_{2} / \mathrm{FiO}_{2}$, which was 300 or less, was also significantly lower in group $\mathrm{S}$ than in group $\mathrm{D}$. 
Table 1. Characteristics of Patients

\begin{tabular}{|c|c|c|c|}
\hline Variable & Group D $(n=26)$ & Group S $(n=28)$ & P value \\
\hline Age (yr) & $34.0(23,38)$ & $36.0(25.7,43.0)$ & NS \\
\hline $\operatorname{Sex}(M / F)$ & $6 / 20$ & $9 / 19$ & NS \\
\hline ASA class & $2.0(1,2)$ & $2.0(2,2)$ & NS \\
\hline MGFA (I/Ila/Ilb/IIla) & $12 / 12 / 2 / 0$ & $15 / 8 / 4 / 1$ & NS \\
\hline Pyridostigmine (mg/d) & $360(225,480)$ & $360(195,465)$ & NS \\
\hline Height $(\mathrm{cm})$ & $163.5(159.0,168.4)$ & $164.7(159.6,170)$ & NS \\
\hline Weight (kg) & $57.5(50.4,72.1)$ & $62.4(53.4,71.1)$ & NS \\
\hline $\operatorname{BMl}\left(\mathrm{kg} / \mathrm{m}^{2}\right)$ & $21.2(20.2,23.5)$ & $22.3(19.7,25.2)$ & NS \\
\hline Operation time (min) & $243.0(200,300)$ & $210.0(176.2,308.8)$ & 0.012 \\
\hline Anesthesia time (min) & $308.5(268.5,359.7)$ & $272.0(234,303.8)$ & 0.030 \\
\hline ICU stay $(\mathrm{d})$ & $2.0(1,2)$ & $2.0(2,2)$ & NS \\
\hline Hospital stay (d) & $8.0(6.7,11)$ & $8.5(6,14.5)$ & NS \\
\hline Bleeding (ml) & $100.0(37.5,100)$ & $0.00(0,175)$ & NS \\
\hline Input (L) & $1.8(1.4,2.3)$ & $1.8(1.4,2.2)$ & NS \\
\hline Urine (ml) & $302.5(200,393.7)$ & $317.5(172.5,47.5)$ & NS \\
\hline
\end{tabular}

Values are presented as median (1Q, 3Q) or number only. ASA: American Society of Anesthesiologists, MGFA: Myasthenia gravis foundation of America, BMI: body mass index, NS: not significant.

Table 2. Respiratory Variables

\begin{tabular}{|c|c|c|c|c|c|c|c|c|c|}
\hline Variable & TO & T1 & $\mathrm{T} 2$ & T3 & T4 & T5 & T6 & T7 & T8 \\
\hline \multicolumn{10}{|l|}{$\mathrm{EtCO}_{2}$} \\
\hline Group D & $33.0(32,35)$ & $34.0 *(31,34)$ & $38.0 *(35,40)$ & $39.0 *(37,43)$ & $38.0 *(33,46)$ & $40.0(36,45)$ & $42.0(35,44)$ & $42.0 *(40,47)$ & $35.0(32,41)$ \\
\hline Group S & $33.5(31,37)$ & $31.0(30,34)$ & $35.0(33,37)$ & $36.0(34,38)$ & $37.0(34,40)$ & $39.5(36,45)$ & $38.0(36,42)$ & $36.5(34,41)$ & $37.0(33,38)$ \\
\hline \multicolumn{10}{|l|}{$\mathrm{SpO}_{2}$} \\
\hline Group D & $100(99)$ & $100 *(96)$ & $100 *(91)$ & $100 *(96)$ & $100(96)$ & $100(94)$ & $100(95)$ & $100(96)$ & $100(97)^{*}$ \\
\hline Group S & $100(99)$ & $100(99)$ & $100(98)$ & $100(99)$ & $100(99)$ & $100(99)$ & $100(99)$ & $100(98)$ & $100(100)$ \\
\hline \multicolumn{10}{|l|}{$\mathrm{FiO}_{2}$} \\
\hline Group D & $0.5(0.5,0.6)$ & $0.6 *(0.5,1.0)$ & $0.6 *(0.5,1.0)$ & $0.7 *(0.5,1.0)$ & $0.7 *(0.5,1.0)$ & $0.7 *(0.5,1.0)$ & $0.8 *(0.6,1.0)$ & $0.8 *(0.6,1.0)$ & $0.6 *(0.5,1.0)$ \\
\hline Group S & $0.5(0.6,0.6)$ & $0.5(0.5,0.6)$ & $0.5(0.5,0.7)$ & $0.5(0.5,0.7)$ & $0.5(0.5,0.7)$ & $0.5(0.5,0.6)$ & $0.5(0.5,0.6)$ & $0.5(0.5,0.6)$ & $0.5(0.5,0.5)$ \\
\hline \multicolumn{10}{|l|}{ PIP } \\
\hline Group D & $18.5(14,22)$ & $20.5(17,26)$ & $21.0(18,28)$ & $26.0(21,30)$ & $27.0(21,30)$ & $26.0(22,30)$ & $26.0(25,30)$ & $30.0(25,31)$ & $23.0(19,26)$ \\
\hline Group S & $16.5(14,18)$ & $20.0(17,25)$ & $25.0(21,27)$ & $28.0(25,29)$ & $28.0(25,29)$ & $28.0(26,30)$ & $29.5(26,30)$ & $29.0(25,31)$ & $26.0(19,30)$ \\
\hline \multicolumn{10}{|l|}{ RR } \\
\hline Group D & $12.0(10,12)$ & $12.0(10,12)$ & $13.0(10,14)$ & $14.0(13,15)$ & $14.0(13,15)$ & $15.0(14.5,16)$ & $15.0(14,16)$ & $15.0(14,16)$ & $12.0(12,15)$ \\
\hline Group S & $11.5(10,12)$ & $12.0(10,13)$ & $13.0(11,13)$ & $14.0(13,16)$ & $14.0(13,16)$ & $15.0(13,16)$ & $15.5(14,16)$ & $15.0(13,16)$ & $15.0(13,16)$ \\
\hline
\end{tabular}

Hemodynamic variables were not significantly different between the two groups. The present study showed that twolung ventilation was a safer and more effective method during BVET with capnothorax than one-lung ventilation.

The reason for the longer anesthesia time in group $\mathrm{D}$ is presumed to be because it takes more time to insert the double-lumen tube and check the proper position. The operation time was measured continuously from the start of the operation on the right side to completion of the left, so the time of the process of expanding the right lung and depleting the left lung again when moving from right to left was included in the operation time. Therefore, it is difficult to interpret this period as operation time. In addition, since surgery using a single lumen tube was performed after surgery using a double-lumen tube, the possibility that it affected the skill level of the surgeon cannot be excluded. Thus, it is 
Table 3. Arterial Oxygen Index (Partial Pressure of Arterial Oxygen/Fraction of Inspired Oxygen)

\begin{tabular}{cccc}
\hline P/F ratio & Group D $(n=41)$ & Group S $(n=46)$ & $P$ value \\
\hline $\mathrm{PaO}_{2} / \mathrm{FiO}_{2} \leq 300$ & $24(58.5)$ & $6(13.0)$ & $<0.001$ \\
$\mathrm{PaO}_{2} / \mathrm{FiO}_{2} \leq 200$ & $18(43.9)$ & $0(0)$ & $<0.001$ \\
\hline
\end{tabular}

Values are presented as number (\%). The arterial oxygen index is known as the P/F ratio, which is a powerful objective tool to identify acute hypoxemic respiratory failure. $\mathrm{PaO}_{2} / \mathrm{FiO}_{2} \leq 300$ indicates mild, and $\mathrm{PaO} 2 / \mathrm{FiO}_{2} \leq 200$ indicates moderate acute respiratory failure. $\mathrm{n}$ : arterial blood gas analysis, $\mathrm{PaO}_{2}$ : partial pressure of arterial oxygen, $\mathrm{FiO}_{2}$ : fraction of inspired oxygen, $\mathrm{P} / \mathrm{F}: \mathrm{PaO}_{2} / \mathrm{FiO}_{2}$.

Table 4. Hemodynamic Variables

\begin{tabular}{|c|c|c|c|c|c|c|c|c|c|}
\hline Variable & T0 & $\mathrm{T} 1$ & $\mathrm{~T} 2$ & T3 & T4 & T5 & T6 & T7 & T8 \\
\hline \multicolumn{10}{|c|}{$\mathrm{Cl}\left(\mathrm{L} / \mathrm{min} / \mathrm{m}^{2}\right)$} \\
\hline Group D & NS & $2.8(2.4,3.3)$ & $2.8(2.4,3.3)$ & $2.5(2.1,3.1)$ & $2.7(2.3,3.2)$ & $3.1(2.4,3.9)$ & $3.4(2.5,3.9)$ & $3.2(2.4,3.8)$ & $3.3(2.9,4.2)$ \\
\hline Group S & NS & $2.6(1.9,3.6)$ & $2.8(2.1,3.5)$ & $2.6(2.1,3.0)$ & $2.6(2.1,3.1)$ & $2.8(1.9,3.3)$ & $2.7(2.3,3.1)$ & $3.0(2.3,3.4)$ & $3.1(2.8,3.9)$ \\
\hline \multicolumn{10}{|c|}{ MBP (mmHg) } \\
\hline Group D & $\begin{array}{c}93.0 \\
(82,111)\end{array}$ & $\begin{array}{c}89.0 \\
(81,94)\end{array}$ & $\begin{array}{c}87.0 \\
(81,95)\end{array}$ & $\begin{array}{c}81.5 \\
(75,2.3)\end{array}$ & $\begin{array}{c}87.0 \\
(80.2,94.7)\end{array}$ & $\begin{array}{c}81.5 \\
(76.7,87.2)\end{array}$ & $\begin{array}{c}84.0 \\
(74.0,94.0)\end{array}$ & $\begin{array}{c}84.5 \\
(70.3,86.0)\end{array}$ & $\begin{array}{c}84.0 \\
(77,91)\end{array}$ \\
\hline Group S & $\begin{array}{c}90.5 \\
(74.5,104.5)\end{array}$ & $\begin{array}{c}87.0 \\
82.0,98.3)\end{array}$ & $\begin{array}{c}88.0 \\
(80.2,94.5)\end{array}$ & $\begin{array}{c}83.0 \\
(77.0,93.0)\end{array}$ & $\begin{array}{c}85.5 \\
(77.0,91.0)\end{array}$ & $\begin{array}{c}86.0 \\
(77.5,97.3)\end{array}$ & $\begin{array}{c}85.5 \\
(78.5,91.0)\end{array}$ & $\begin{array}{c}82.5 \\
(75.0,92.5)\end{array}$ & $\begin{array}{c}88.0 \\
(81.5,95.8)\end{array}$ \\
\hline \multicolumn{10}{|c|}{ HR (beats/min) } \\
\hline Group D & $\begin{array}{c}76.0 \\
(63.0,85.0)\end{array}$ & $\begin{array}{c}67.5 \\
(63.3,72.3)\end{array}$ & $\begin{array}{c}74.0 \\
(66.5,87.8)\end{array}$ & $\begin{array}{c}77.0 \\
(65.5,87.8)\end{array}$ & $\begin{array}{c}78.5 \\
(67.0,89.5)\end{array}$ & $\begin{array}{c}83.5 \\
(67.0,89.5)\end{array}$ & $\begin{array}{c}82.0 \\
(72.0,95.0)\end{array}$ & $\begin{array}{c}84.5 \\
(74.0,90.3)\end{array}$ & $\begin{array}{c}75.0 \\
(66.5,85.5)\end{array}$ \\
\hline Group S & $\begin{array}{c}76.5 \\
(64.5,86.5)\end{array}$ & $\begin{array}{c}66.5 \\
(59.3,76.0)\end{array}$ & $\begin{array}{c}73.0 \\
(65.8,79.0)\end{array}$ & $\begin{array}{c}73.0 \\
(64.0,76.0)\end{array}$ & $\begin{array}{c}70.5 \\
(64.0,79.0)\end{array}$ & $\begin{array}{c}75.0 \\
(66.3,87.3)\end{array}$ & $\begin{array}{c}71.5 \\
(65.0,87.3)\end{array}$ & $\begin{array}{c}73.0 \\
(63.3,84.3)\end{array}$ & $\begin{array}{c}70.5 \\
(57.2,75.0)\end{array}$ \\
\hline
\end{tabular}

Values are presented as the median (1Q, 3Q). T0: immediately after tracheal intubation, T1: right-side incision time, T2: 10 min after right lung $\mathrm{CO}_{2}$ insufflation, T3: 30 min from right lung $\mathrm{CO}_{2}$ insufflation, T4: the transition period from the right to the left side (in group D, two-lung ventilation), T5-T8: the same as T1-T4 of the left side, Cl: cardiac index, MBP: mean blood pressure, HR: heart rate, NS: not significant.

debatable whether the use of a single lumen tube during BVET reduces the operation time.

$\mathrm{EtCO}_{2}$ was higher in group D than in group S, from T1 to T3. The difference between the two groups was no longer observed after T4, which can be estimated as the residual $\mathrm{CO}_{2}$ effect after operation on the right side. In the case of $\mathrm{SpO}_{2}$, the median value between the two groups was not different; however, due to the difference in the minimum values, the $\mathrm{SpO}_{2}$ from $\mathrm{T} 1$ to $\mathrm{T} 3$ in group $\mathrm{D}$ was lower than that in group S. After T4, the difference between the two groups was no longer observed, which can be interpreted to be a result of the increase in the $\mathrm{FiO}_{2}$ value of group $\mathrm{D}$ over time. This is interpreted to mean that $\mathrm{FiO}_{2}$ had to be increased in group $\mathrm{D}$ to maintain adequate $\mathrm{SpO}_{2}$ for the patient.

The effectiveness and side effects of $\mathrm{CO}_{2}$ insufflation in VATS are controversial. Ohtsuka et al. [6] reported that lowflow $\mathrm{CO}_{2}$ insufflation does not compromise the human heart with normal to moderately depressed function and can be an efficacious adjunct in specific thoracoscopic procedures. In contrast, Brock et al. [10] investigated the hemodynamic and respiratory effects of one-lung ventilation and $\mathrm{CO}_{2}$ insufflation in 13 adult patients undergoing VATS. They suggested that the combined use of one-lung ventilation and $\mathrm{CO}_{2}$ insuf- flation increases the hazards, as both hypoxia and low CI are expected. In our study, although the $\mathrm{O}_{2}$ index $<300$ was higher in group $\mathrm{D}$ than in group $\mathrm{S}$, hypoxia $\left(\mathrm{SpO}_{2}<90 \%\right)$ and hemodynamic exacerbation were not observed. Hence, the results were different from those reported by Brock et al. [10].

After Brock et al. [10]'s study, researchers attempted to avoid one-lung ventilation in the presence of capnothorax. No active clinical studies have been conducted since the publication of this study. However, it was difficult to prevent the introduction of capnothorax with one-lung ventilation in a field where minimally invasive surgery was developed and actively introduced into the clinic. It is notable that one-lung ventilation was safely used with capnothorax in BVET in hospitals that actively utilized BVET before our hospital did [11]. Nevertheless, ventilation during $\mathrm{CO}_{2}$ insufflation should be titrated to maintain adequate oxygenation and a normal $\mathrm{PCO}_{2}$ and $\mathrm{pH}$. Anesthesiologists must be aware that damage to the contralateral pleura may occur, resulting in $\mathrm{CO}_{2}$ flow to the contralateral chest, making ventilation difficult and resulting in tension pneumothorax or severe subcutaneous emphysema, which subsequently produces a hemodynamic compromise [2].

Recently, single lumen tube and $\mathrm{CO}_{2}$ insufflation have 
been considered safe alternative treatments for one-lung ventilation because they reduce the side effects caused by the double-lumen tube, shorten the duration of surgery and anesthesia, and allow anesthesia to be performed by inexpert anesthesiologists [12-16]. However, in their studies, two-lung ventilation in the presence of capnothorax and one-lung ventilation in the absence of capnothorax were compared. In the present study, one-lung ventilation and two-lung ventilation were compared with various variables in the presence of capnothorax, which is different from the results of other studies. Although the results of our study showed that two-lung ventilation in the presence of capnothorax is a better anesthetic method, it should be noted that there are various risks of $\mathrm{CO}_{2}$ insufflation, such as venous gas embolism, compromised venous return, severe bradycardia, and progressive arterial desaturation [17].

Upon clarification with the surgeon, the only thoracic surgeon in our hospital, it was noted that he was satisfied with both anesthetic methods. However, most anesthesiologists and anesthesiology residents prefer two-lung ventilation. Failure to investigate the satisfaction score is one of the limitations of this study.

Thymectomy for MG is the most frequently performed surgery in our hospital in South Korea. This is possibly because the diagnoses and treatment consultations of MG patients are active between the MG specialty center and our hospital. If a neurologist at the MG specialty center refers patients to our hospital, a neurologist, thoracic surgeon, and anesthesiologist at our hospital discuss patient surgery. After the operation, the patient is referred to the MG specialty center again. The indications for surgical treatment of patients with MG have not yet been clearly established. The American Academy of Neurology published the international consensus guidelines for the management of MG [18]. In non-thymomatous MG, thymectomy is performed as an option to avoid or minimize the dose or duration of immunotherapy, or if patients fail to respond to an initial trial of immunotherapy or have intolerable side effects from that therapy. In our center, the occurrence of clinical symptoms with an ACh receptor antibody positivity within 5 years of symptom onset and age 18-65 years are considered indications for surgery.

MG patients may experience two crises: cholinergic crisis and myasthenic crisis. A cholinergic crisis is usually caused by an excess of cholinesterase inhibitors. Hypersalivation, sweating, abdominal cramps, bradycardia, and muscle weakness may occur. A myasthenic crisis, which refers to a life-threatening condition that is defined as the worsening of myasthenic weakness requiring intubation or noninvasive ventilation, can be triggered by emotional and physical stress, such as infections, certain medications, and surgery [19]. Postoperative myasthenic crisis with respiratory muscle paralysis can be a severe complication and reportedly occurs in $12-18 \%$ of patients. Kanai et al. [20] reported that the significant preoperative clinical predictive factors for postoperative myasthenic crises were percentage VC $<80 \%$ (3 points), duration of MG before thymectomy $<3$ months (2 points), and bulbar symptoms immediately before thymectomy ( 1 point), with scores ranging from 0 to 6 . Myasthenic crises were observed in $0.9 \%$ of patients with scores $<3$ vs. $25.9 \%$ of patients with scores $\geq 3$. There were no cases of post-thymectomy myasthenic crisis in our study. Limitations were observed in the present study as the investigations were conducted only up to $24 \mathrm{~h}$ postoperatively; however, the patients included in this study were able to determine that no postoperative myasthenic crisis occurred because the VC was normal and patients with low MGFA grades accounted for the majority.

This study has some limitations. As with all retrospective studies, there were several missing data; hence, the number of patients was smaller than planned. Additionally, it was impossible to compare the $\mathrm{O}_{2}$ index at each time point because arterial blood gas analysis was not performed at a fixed time.

In conclusion, this retrospective study suggests that anesthesia using two-lung ventilation during BVET with capnothorax is a safe and effective method to improve lung oxygenation and reduce anesthesia time.

\section{FUNDING}

None.

\section{CONFLICTS OF INTEREST}

No potential conflict of interest relevant to this article was reported.

\section{DATA AVAILABILITY STATEMENT}

Data sharing not applicable to this article as no datasets were generated or analyzed during the current study. 


\section{AUTHOR CONTRIBUTIONS}

Conceptualization: Mijung Yun, Gunn Hee Kim. Data curation: Sung-chul Ko. Formal analysis: Gunn Hee Kim. Methodology: Gunn Hee Kim. Project administration: Gunn Hee Kim, Wooshik Kim. Visualization: Gunn Hee Kim, Wooshik Kim. Writing - original draft: Mijung Yun. Writing - review \& editing: Mijung Yun, Gunn Hee Kim. Investigation: Sung-chul Ko, Yun Jae Han. Resources: Sung-chul Ko, Yun Jae Han, Wooshik Kim. Software: Wooshik Kim. Supervision: Gunn Hee Kim, Wooshik Kim.

\section{ORCID}

Mijung Yun, https://orcid.org/0000-0001-5838-4893

Gunn Hee Kim, https://orcid.org/0000-0002-0014-8297

Sung-chul Ko, https://orcid.org/0000-0001-8460-2962

Yun Jae Han, https://orcid.org/0000-0002-4027-786X

Wooshik Kim, https://orcid.org/0000-0003-2787-2186

\section{REFERENCES}

1. Blichfeldt-Lauridsen L, Hansen BD. Anesthesia and myasthenia gravis. Acta Anaesthesiol Scand 2012; 56: 17-22.

2. Campos J, Ueda K. Update on anesthetic complications of robotic thoracic surgery. Minerva Anestesiol 2014; 80: 83-8.

3. Cooper JD. History of thymectomy for myasthenia gravis. Thorac Surg Clin 2019; 29: 151-8.

4. Ye B, Tantai JC, Ge XX, Li W, Feng J, Cheng M, et al. Surgical techniques for early-stage thymoma: video-assisted thoracoscopic thymectomy versus transsternal thymectomy. J Thorac Cardiovasc Surg 2014; 147: 1599-603.

5. Ye B, Tantai JC, Li W, Ge XX, Feng J, Cheng M, et al. Video-assisted thoracoscopic surgery versus robotic-assisted thoracoscopic surgery in the surgical treatment of Masaoka stage I thymoma. World J Surg Oncol 2013; 11: 157.

6. Ohtsuka T, Imanaka K, Endoh M, Kohno T, Nakajima J, Kotsuka Y, et al. Hemodynamic effects of carbon dioxide insufflation under single-lung ventilation during thoracoscopy. Ann Thorac Surg 1999; 68: 29-32. discussion 32-3.

7. Tomescu D, Grigorescu B, Nitulescu R, Tomulescu V, Popescu I, Tulbure D. [Hemodynamic changes induced by positive pressure capnothorax during thoracoscopic thymectomy]. Chirurgia (Bucur) 2007; 102: 263-70. Romanian.

8. Witt L, Osthaus WA, Schröder T, Teich N, Dingemann C, Kübler
J, et al. Single-lung ventilation with carbon dioxide hemipneumothorax: hemodynamic and respiratory effects in piglets. Paediatr Anaesth 2012; 22: 793-8.

9. Jones DR, Graeber GM, Tanguilig GG, Hobbs G, Murray GF. Effects of insufflation on hemodynamics during thoracoscopy. Ann Thorac Surg 1993; 55: 1379-82.

10. Brock H, Rieger R, Gabriel C, Pölz W, Moosbauer W, Necek S. Haemodynamic changes during thoracoscopic surgery the effects of one-lung ventilation compared with carbon dioxide insufflation. Anaesthesia 2000; 55: 10-6.

11. Lee CY, Kim DJ, Lee JG, Park IK, Bae MK, Chung KY. Bilateral video-assisted thoracoscopic thymectomy has a surgical extent similar to that of transsternal extended thymectomy with more favorable early surgical outcomes for myasthenia gravis patients. Surg Endosc 2011; 25: 849-54.

12. Caso R, Kelly CH, Marshall MB. Single lumen endotracheal intubation with carbon dioxide insufflation for lung isolation in thoracic surgery. Surg Endosc 2019; 33: 3287-90.

13. Sancheti MS, Dewan BP, Pickens A, Fernandez FG, Miller DL, Force SD. Thoracoscopy without lung isolation utilizing single lumen endotracheal tube intubation and carbon dioxide insufflation. Ann Thorac Surg 2013; 96: 439-44.

14. Zhang R, Liu S, Sun H, Liu X, Wang Z, Qin J, et al. The application of single-lumen endotracheal tube anaesthesia with artificial pneumothorax in thoracolaparoscopic oesophagectomy. Interact Cardiovasc Thorac Surg 2014; 19: 308-10.

15. Javid MJ, Toolabi K, Aminian A. Two lung ventilation through single lumen tracheal tube in thoracoscopic thymectomy: a randomized clinical trial of efficacy and safety. Middle East J Anaesthesiol 2008; 19: 1361-8.

16. El-Dawlatly A, Al-Dohayan A, Riyad W, Thalaj A, Delvi B, AlSaud S. Thoracoscopic sympathectomy: endobronchial anesthesia vs endotracheal anesthesia with intrathoracic CO2 insufflation. J Anesth 2002; 16: 13-6.

17. Steenwyk B, Lyerly R 3rd. Advancements in robotic-assisted thoracic surgery. Anesthesiol Clin 2012; 30: 699-708.

18. Sanders DB, Wolfe GI, Benatar M, Evoli A, Gilhus NE, Illa I, et al. International consensus guidance for management of myasthenia gravis: executive summary. Neurology 2016; 87: 419-25.

19. Carron M, De Cassai A, Linassi F. Sugammadex in the management of myasthenic patients undergoing surgery: beyond expectations. Ann Transl Med 2019; 7(Suppl 8): S307.

20. Kanai T, Uzawa A, Sato Y, Suzuki S, Kawaguchi N, Himuro K, et al. A clinical predictive score for postoperative myasthenic crisis. Ann Neurol 2017; 82: 841-9. 